\title{
Early Expression of Apical Control Regulates Length and Crotch Angle of Sylleptic Shoots in Peach and Nectarine
}

\author{
Nigel C. Cook, Etienne Rabe, and Gerard Jacobs \\ Department of Horticultural Science, University of Stellenbosch, Private Bag \\ X1, Matieland 7602, Stellenbosch, South Africa
}

Additional index words. branching dynamics, apical dominance, growth habit, shoot
autonomy, Prunus persica

\begin{abstract}
Syllepsis is the predominant mode of branching in young peach and nectarine trees [Prunus persica (L.) Batsch]. Cultivars differ considerably in expression of apical control of sylleptic shoots. This has practical implications regarding tree training. Four cultivars were selected for increasing apical control by the central shoot axis, viz., 'Zaigina', 'Mayglo', 'Fiesta Red' (all nectarines), and 'Oom Sarel' (clingstone peach), respectively. Young, actively growing shoots were harvested when $\approx 300 \mathrm{~mm}$ in length, at a time when development of sylleptic shoots (laterals) had begun. Length, crotch angle, and position (as distance from the apex) of the laterals were recorded. When length of the laterals was plotted against their position, two zones were observed. The gradient of length vs. position was shallower in the distal than in the proximal zone. Autonomy in lateral shoots can be described as their ability to grow independently of apical control by the apex of the branch. Autonomy of laterals near the branch apex increased with their length. In 'Zaigina' this was established via a more distal start of the second zone, and in 'Mayglo' via an increased gradient in the second zone. The early loss or maintenance of apical control regulates architecture in sylleptically branched peach and nectarine shoots. Crotch angle widening of laterals appears to be largely dependent on position, but in some cultivars, such as 'Mayglo', other factors are also involved. The data provide evidence of correlative phenomena between actively growing shoots.
\end{abstract}

Syllepsis, one mode of branching in young peach and nectarine trees, is described by Hallé et al. (1978) as "the continuous development of a lateral [axillary] from a terminal meristem to establish a branch, without an intervening period of rest of that lateral [axillary] meristem." Branching therefore occurs simultaneously with elongation of the parent axis. The resultant branches are referred to as sylleptic branches. This sequential branching habit on an axis that continues elongation results in a conical form. This form results from weak apical dominance and strong apical control(Brownetal., 1967; Champagnat, 1954; Crabbé, 1987). Apical control implies a correlative suppression by the dominant central shoot axis on lateral shoot extension and orientation (more horizontal), i.e., correlations between shoots.

The architectural model of Rauh describes the overall growth model of the peach and nectarine tree due to the rhythmic nature of growth (over seasons) (Hallé et al., 1978).

Received for publication 11 May 1998. Accepted for publication 10 Nov 1998. We thank Dr. J.H. Randall (Biometrician, Faculty of Agricultural Science, Univ. of Stellenbosch) for assistance with the data analysis. The cost of publishing this paper was defrayed in part by the payment of page charges. Under postal regulations, this paper therefore must be hereby marked advertisement solely to indicate this fact.
However, within a growth flush (one season), Attim's architectural model more accurately describes the formation of a sylleptically branched complex. Growth of the central axis is continuous, monopodial, and tends towards the orthotropic orientation. Sylleptic branching is diffuse, as not all axillary buds elongate (as with continuous branching). Because of the sequence of development, sylleptic shoots (laterals) adhere to a defined hierarchy. The initial laterals develop near the base of the central axis and are the most mature and longest. The more distal laterals are younger and are correspondingly shorter; hence the conical form. Thus, during the early stage of development the central shoot axis expresses apical control (Cline, 1997), resulting in a branching hierarchy that is predetermined by the sylleptic branching habit.

The capacity of peach and nectarine to form sylleptic shoots is utilized in South Africa when training young trees (Strydom, 1991). Newly planted nursery trees are headed back to $20 \mathrm{~cm}$ above the graft union to induce vigorous shoot growth. These vigorous shoots readily form laterals. However, characteristic differences exist among cultivars in the form of the branched shoots (personal observation). In some upright-growing cultivars, apical control by the central shoot axis does not persist for the entire growing period, but is soon lost. The initial (oldest and most proximal) laterals compete strongly with the central axis, resulting in a branched complex with many vigorously growing axes. These laterals become codominant, and thus develop autonomy (Cook et al., 1998). When apical control by the central shoot axis is weak, other axes within the branched complex grow independently of the axis (are autonomous) and, thus, a polyarchic architecture results. In contrast, the central shoot axis in more spreading cultivars maintains apical control, resulting in a complex branch with a well-defined conical form and a hierarchy between the central shoot axis and the subtending laterals whose growth it regulates. Lauri et al. (1995) describe hierarchic and polyarchic tree architecture in apple (Malus $\times$ domestica Borkh.) trees. In hierarchic cultivars, a dominant central leader maintains clear definition between the trunk and subordinate branches; the axes of polyarchic cultivars tend to become equivalent.

Commercially, polyarchy (basal dominance) in central leader systems is undesirable because more pruning and training are required and this delays production. The purpose of this study was to identify, at an early developmental stage, parameters of sylleptic shoot growth that either increase shoot autonomy (polyarchic architecture) or, alternatively, maintain apical control (hierarchic architecture).

\section{Materials and Methods}

Four cultivars were selected with decreasing shoot autonomy and increased apical control, viz., the nectarine cultivars Zaigina, Mayglo, and Fiesta Red, and the locally bred yellow clingstone peach cultivar Oom Sarel.

Actively growing watersprouts ( 10 or 11 per cultivar) of 'Zaigina', 'Mayglo', 'Fiesta Red', and 'Oom Sarel' were collected from bearing, commercial orchards near Stellenbosch (lat. $34^{\circ} \mathrm{S}$ ) on 17 Oct., 12 Oct., 12 Oct., and 26 Oct. 1995, respectively. All the orchards, which exhibited normal vigor and production, were trained to a "Central Leader" system described by Strydom (1991). Winter pruning stimulates the production of watersprouts, on which numerous laterals develop. These watersprouts are reiterations that conform to the same architectural model as that of the parent tree (Hallé et al., 1978), and can be assumed to be homologous with the initial stages of growth of the scion in young (first leaf) trees. Only the more vigorous, orthotropic shoots from outer positions on the tree were sampled. The time of budburst differed with cultivar, but on the above harvest dates the most vigorous shoots were all $\approx 300 \mathrm{~mm}$ long, and recently developed laterals were clearly visible. All leaves were removed from these branched complexes (branches) to clearly reveal the shoot apex of the laterals and the central shoot axis.

On each branch, the length, crotch angle (degrees from vertical as determined with a clear plastic protractor), and position of each lateral were recorded within $300 \mathrm{~mm}$ of the apex. Data were analyzed only for laterals adhering to a hierarchy, i.e., each consecutive lateral had to be as long as or longer than the lateral distal to it. Any lateral shorter than a more distal lateral was considered stunted; such laterals do not develop into scaffold 
branches. Lateral length and crotch angle at the branch apex were assumed to be zero. The method described by Littell (1989) was used to determine the double- or triple-phase growth responses for length and crotch angle of laterals relative to position (Fig. 1). For statistical analyses, CORR (correlation), GLM (general linear models), and NLIN (nonlinear regression) procedures of SAS, version 6.12 (SAS Institute, 1996), were used.

\section{Results and Discussion}

In all cultivars, both lateral length and crotch angle were highly and positively correlated with distance from the branch apex (Table 1). The high correlation between lateral length and crotch angle suggests similar dependence on position. When position was held constant, not all cultivars showed the same relationship between lateral length and crotch angle. The low correlation coefficient $(r)$ values for 'Zaigina', 'Fiesta Red', and 'Oom Sarel' imply that crotch angle is predominantly determined by position in these cultivars. In 'Mayglo' other factors are involved, e.g., lateral length.

Among cultivars, significant differences were observed in lateral length but not in crotch angle (Table 2). Lateral length increased as the tendency towards polyarchic architecture increased ('Zaigina' relative to 'Oom Sarel'). After adjustment (position held constant), differences among cultivars were significant for both lateral length and crotch angle. 'Oom Sarel' exhibited short laterals and the widest crotch angles. 'Zaigina' had the longest laterals and narrower crotch angles. 'Mayglo' and 'Fiesta Red' were intermediate; both had narrow crotches but 'Mayglo' had longer laterals than did 'Fiesta Red'.

When length was plotted against position, two zones were observed. Length changed little in the distal zone, then rose steadily with distance (Fig. 1). The method described by Littell (1989) was used to calculate the first and second gradients, and the position of change in gradient. This model was fitted to the data for each individual branch, and the model parameters were subjected to analysis of variance (ANOVA) (Fig. 2A, Table 3). 'Zaigina' showed the shallowest and 'Mayglo' the steepest initial gradient. The gradient of the second zone was similar for 'Zaigina', 'Fiesta Red', and 'Oom Sarel', but significantly steeper in 'Mayglo'. The position of gradient change was closest to the apex for 'Zaigina', followed by 'Oom Sarel', 'Fiesta Red', and 'Mayglo'.

When crotch angle was plotted vs. position, three zones were observed (Fig. 1B). Laterals close to the apex remained flush with the central axis and crotches did not widen (Fig. 2B and Table 3). In the second zone, the crotch angle increased with distance from the apex. In most branches a third zone with a reduced gradient was observed, but not always. As a result, the ANOVA between cultivars for some parameters of the crotch angle widening model, i.e., the third gradient and the second position of gradient change, was esti-

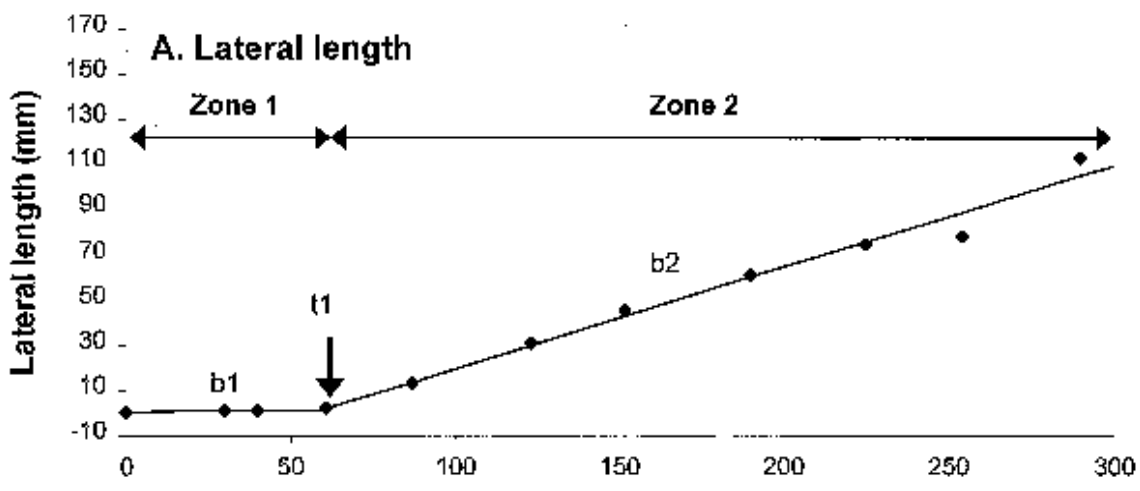

40 B. Crotch angle

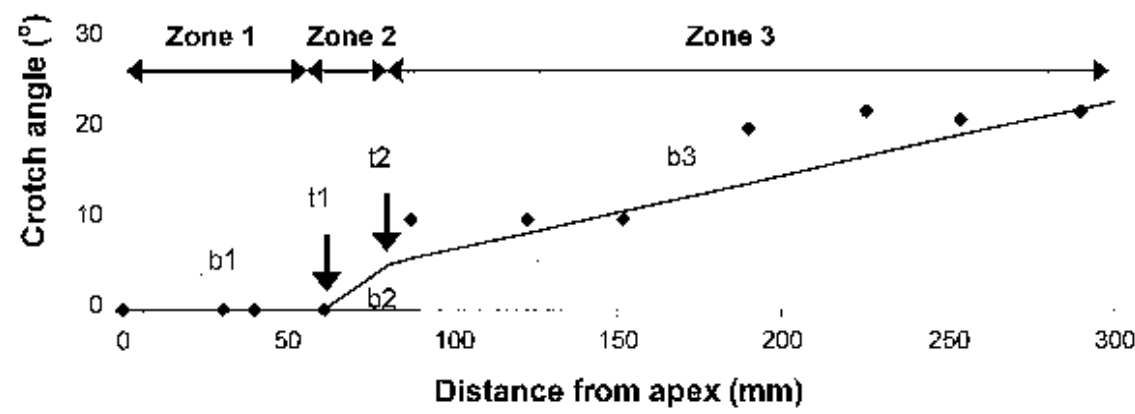

Fig. 1. (A) Lateral shoot length and (B) crotch angle relative to position on the axis of one (arbitrarily chosen) sylleptically branched shoot of Prunus persica . Diamonds = actual data; lines = fitted models. Model parameters: $b_{1}=$ initial zone gradient $b_{2}=$ second zone gradient; $b_{3}=$ third zone gradient $; t_{1}=$ first position of gradient change; $\mathrm{t}_{2}=$ second position of gradient change.

Table 1. Correlations $(r)$ between the architectural components within the sylleptically branched shoots of four cultivars of Prunus persica.

\begin{tabular}{|c|c|c|c|c|c|c|c|c|}
\hline \multirow[b]{3}{*}{ Component } & \multicolumn{8}{|c|}{ Cultivar } \\
\hline & \multicolumn{2}{|c|}{ Zaigina } & \multicolumn{2}{|c|}{ Mayglo } & \multicolumn{2}{|c|}{ Fiesta Red } & \multicolumn{2}{|c|}{ Oom Sarel } \\
\hline & $\begin{array}{l}\text { Lateral } \\
\text { length }\end{array}$ & $\begin{array}{c}\text { Crotch } \\
\text { angle }\end{array}$ & $\begin{array}{l}\text { Lateral } \\
\text { length }\end{array}$ & $\begin{array}{c}\text { Crotch } \\
\text { angle }\end{array}$ & $\begin{array}{l}\text { Lateral } \\
\text { length }\end{array}$ & $\begin{array}{c}\text { Crotch } \\
\text { angle }\end{array}$ & $\begin{array}{l}\text { Lateral } \\
\text { length }\end{array}$ & $\begin{array}{c}\text { Crotch } \\
\text { angle }\end{array}$ \\
\hline Position & 0.975 & 0.922 & 0.922 & 0.862 & 0.911 & 0.878 & 0.896 & 0.884 \\
\hline Significance $^{\mathrm{z}}$ & 0.0001 & 0.0001 & 0.0001 & 0.0001 & 0.0001 & 0.0001 & 0.0001 & 0.0001 \\
\hline Lateral length & --- & 0.923 & --- & 0.925 & --- & 0.834 & --- & 0.857 \\
\hline Significance & --- & 0.0001 & --- & 0.0001 & --- & 0.0001 & --- & 0.0001 \\
\hline Lateral length ${ }^{y}$ & --- & 0.273 & --- & 0.661 & --- & 0.173 & --- & 0.313 \\
\hline Significance & --- & 0.0001 & --- & 0.0001 & --- & 0.1928 & --- & 0.0099 \\
\hline
\end{tabular}

${ }^{2}$ Significance level for Pearson Correlation Coefficients.

yPartial correlation coefficient between lateral shoot length and crotch angle with position held constant.

Table 2. Effects of cultivar of Prunus persica on lateral shoot length and crotch angle (degrees) in sylleptically branched shoots.

\begin{tabular}{|c|c|c|c|c|}
\hline & \multicolumn{2}{|c|}{ Means not adjusted } & \multicolumn{2}{|c|}{$\begin{array}{l}\text { Means adjusted using } \\
\text { position as covariate }\end{array}$} \\
\hline & $\begin{array}{l}\text { Lateral length } \\
(\mathrm{mm})\end{array}$ & $\begin{array}{c}\text { Crotch angle } \\
\left({ }^{\circ}\right)\end{array}$ & $\begin{array}{l}\text { Lateral length } \\
(\mathrm{mm})\end{array}$ & $\begin{array}{c}\text { Crotch angle } \\
\left({ }^{\circ}\right) \\
\end{array}$ \\
\hline$\overline{\text { Zaigina }(\mathrm{n}=11)^{\mathrm{z}}}$ & $40 \mathrm{a}^{\mathrm{y}}$ & 8.8 & $39 \mathrm{a}$ & $8.4 \mathrm{~b}$ \\
\hline Mayglo $(n=10)$ & $36 \mathrm{a}$ & 7.3 & $33 \mathrm{~b}$ & $6.6 \mathrm{c}$ \\
\hline Fiesta Red $(n=11)$ & $31 \mathrm{ab}$ & 7.4 & $29 \mathrm{c}$ & $7.0 \mathrm{bc}$ \\
\hline Oom Sarel $(\mathrm{n}=10)$ & $23 \mathrm{~b}$ & 9.1 & $29 \mathrm{c}$ & $10.6 \mathrm{a}$ \\
\hline \multicolumn{5}{|l|}{ Significance } \\
\hline Position & --- & --- & 0.0001 & 0.0001 \\
\hline Cultivar & 0.0214 & 0.5730 & 0.0001 & 0.0001 \\
\hline
\end{tabular}

${ }^{2}$ Number of branched complexes sampled.

${ }^{y}$ Mean separation within columns by LSD, $P=0.05$. 

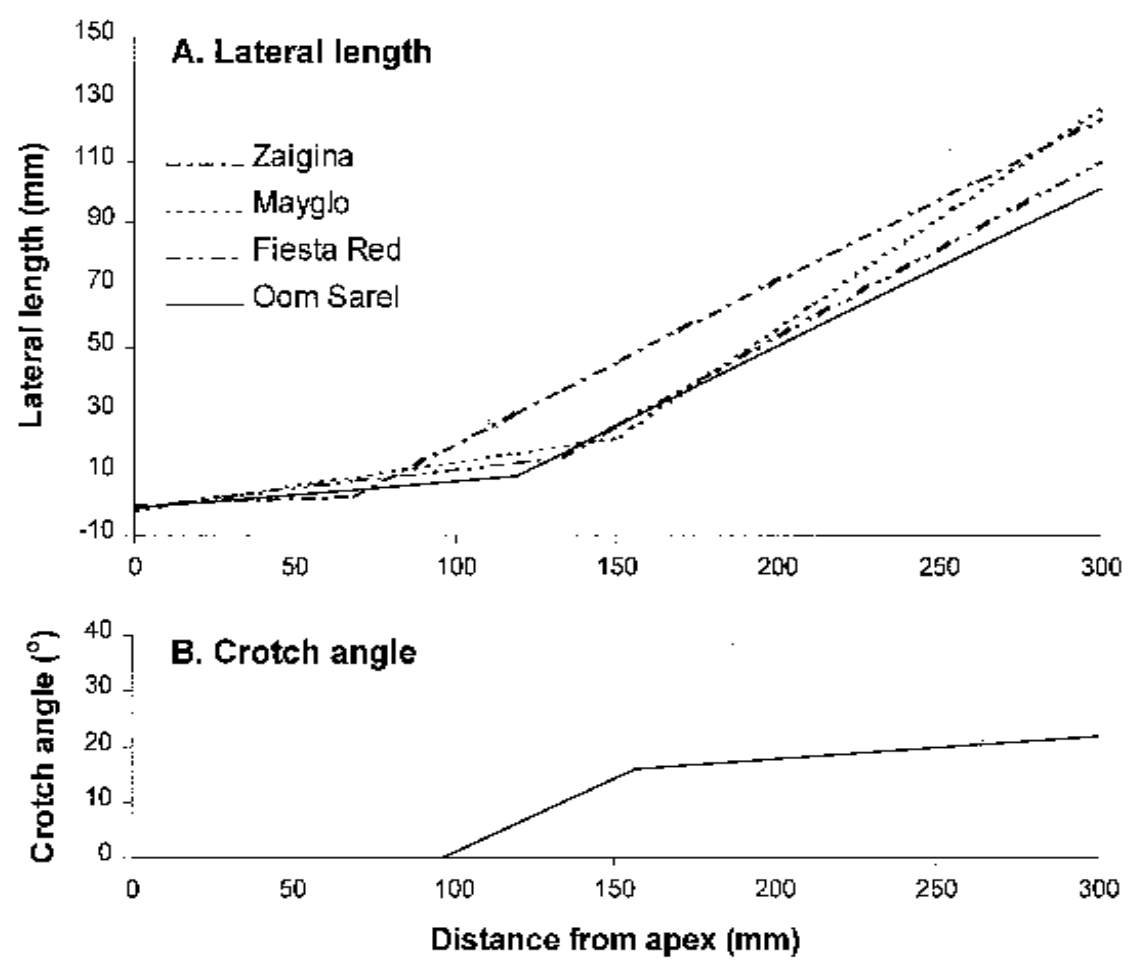

Fig. 2. (A) Lateral shoot length and (B) crotch angle relative to position on the axis of sylleptically branched shoots of each of four cultivars of Prunus persica. The model parameters for crotch angle did not differ significantly between cultivars; therefore, only the means (for all cultivars) are presented.

Table 3. Model parameters for lateral shoot length and crotch angle relative to position on the shoot axis of each of four cultivars of Prunus persica. The model parameters for crotch angle did not differ significantly between cultivars; therefore, only the means (for all cultivars) are presented.

\begin{tabular}{lccccr}
\hline \hline & \multicolumn{5}{c}{ Model parameters $^{\mathrm{z}}$} \\
\cline { 2 - 6 } Cultivar & $\mathrm{b}_{1}$ & $\mathrm{~b}_{2}$ & $\mathrm{~b}_{3}$ & $\mathrm{t}_{1}$ & $\mathrm{t}_{2}$ \\
\hline & & & Lateral length $^{z}$ & & \\
Zaigina & $0.035 \mathrm{a}^{\mathrm{y}}$ & $0.526 \mathrm{a}$ & --- & $69 \mathrm{a}$ & --- \\
Mayglo & $0.153 \mathrm{~b}$ & $0.715 \mathrm{~b}$ & --- & $152 \mathrm{~b}$ & --- \\
Fiesta Red & $0.121 \mathrm{c}$ & $0.572 \mathrm{a}$ & -- & $134 \mathrm{c}$ & --- \\
Oom Sarel & $0.085 \mathrm{~d}$ & $0.509 \mathrm{a}$ & --- & $119 \mathrm{~d}$ & -- \\
Significance & 0.0001 & 0.0742 & --- & 0.0001 & --- \\
& & & Crotch angle & & \\
All cultivars & 0 & 0.265 & 0.043 & 97 & 157
\end{tabular}

${ }^{2}$ Model parameters: $b_{1}=$ initial zone gradient; $b_{2}=$ second zone gradient; $b_{3}=$ third zone gradient; $t_{1}=$ first position of gradient change; $\mathrm{t}_{2}=$ second position of gradient change.

${ }^{y}$ Mean separation within columns by LSD, $P=0.05$.

mated using missing values. The calculated model parameters for crotch angle widening relative to position did not differ significantly among cultivars (Table 3 ).

'Zaigina' and 'Oom Sarel' both showed flatter gradients for lateral length $\left(b_{1}\right)$ in the first zone (Fig. 2A, Table 3), as well as wider crotch angles (Table 2). 'Mayglo' and 'Fiesta Red' had both steeper initial gradients for lateral length $\left(\mathrm{b}_{1}\right)$ (Fig. 2A, Table 3), and narrower crotch angles (Table 2). While the region of crotch angle widening is fixed, the final crotch angle may be regulated by the initial elongation rate of the lateral, as shown in apple (Jankiewicz, 1964). This is confirmed by the positive correlation between lateral length and crotch angle when position was held constant in 'Zaigina', 'Mayglo', and 'Oom Sarel' (Table 1).
In 'Zaigina', the most polyarchic (weakest apical control), the position of change in gradient in lateral length $\left(\mathrm{t}_{1}\right)$ was closest to the apex (Fig. 2A, Table 3). 'Mayglo', also polyarchic, while having the most proximal position of gradient change $\left(t_{1}\right)$, had the steepest gradient $\left(b_{2}\right)$ in the second zone (Fig. 2B, Table 3). Thus, 'Mayglo' and 'Zaigina' had the longest laterals, at $\approx 275 \mathrm{~mm}$ from the apex. In 'Fiesta Red' and 'Oom Sarel', both more hierarchic cultivars, the position of gradient change $\left(t_{1}\right)$ was farther from the apex, and gradients $\left(b_{2}\right)$ were shallower in the second zone (Fig. 2A, Table 3). In 'Oom Sarel', the most hierarchic, the flatter initial and second zone gradient $\left(b_{1}\right)$, combined with a more proximal position of gradient change $\left(\mathrm{t}_{1}\right)$, may reflect the stronger apical control (Fig. 2A, Table 3).
Champagnat (1978) describes the formation of sylleptic shoots as the "partial expression" of apical dominance. Complete expression of apical dominance results in no sylleptic branching and a monoaxial shoot. All cultivars in our study exhibited partial apical dominance. Architecture of sylleptically branched complexes cannot be explained solely by the degree of expression of apical dominance; apical control is also important. Weaker apical control permits greater autonomy of laterals and, thus, polyarchy.

Thus, the autonomy of sylleptic shoots appears to be due to 1) a relatively distal change in gradient in lateral length, or 2) a steeper gradient for lateral length in the zone proximal to the position of gradient change. Increased lateral length was associated with a more distal transition to the second zone in 'Zaigina', and to an increased gradient in the second zone in 'Mayglo'. Greater autonomy of the early developing laterals (or loss of apical control by the leader) is associated with increased lateral length. Crotch angle appears to be largely dependent on position, but in some cultivars such as 'Mayglo' other factors are also involved. Our data provide evidence of correlative phenomena between actively growing peach and nectarine shoots.

\section{Literature Cited}

Brown, C.L., R.G. McAlpine, and P.P. Kormanik. 1967. Apical dominance and form in woody plants: A reappraisal. Amer. J. Bot. 54:153-162.

Champagnat, P. 1954. Recherches sur les rameaux anticipés des végétaux ligneux. Rev. Cytol. Biol. Vég. 15:1-51.

Champagnat, P. 1978. Formation of the trunk in woody plants, p. 401-422. In: P.B. Tomlinson and M.H. Zimmermann (eds.). Tropical trees as living systems. Cambridge Univ. Press, Cambridge, U.K.

Cline, M.G. 1997. Concepts and terminology of apical dominance. Amer. J. Bot. 84:1064-1069.

Cook, N.C., E. Rabe, J. Keulemans, and G. Jacobs. 1998. The expression of acrotony in deciduous fruit trees: A study of the apple rootstock M.9. J. Amer. Soc. Hort. Sci. 123:30-34.

Crabbé, J. 1987. Aspects particuliers de la morphogenése caulinaire des végétaux ligneux et introduction à leur étude quantitative. Centre d'Etude de la Reproduction Végétale, Brussels.

Hallé, F., R.A.A. Oldeman, and P.B. Tomlinson. 1978. Tropical trees and forests. An architectural analysis. Springer-Verlag, Berlin.

Jankiewicz, L.S. 1964. Mechanism of crotch angle formation in apple trees. I. The crotches in trees growing a vertical and a horizontal positions [sic]. Acta Agrobot. 15:21-50.

Lauri, P.E., E. Térouanne, J.M. Lespinasse, J.L. Regnard, and J.J. Kelner. 1995. Genotypic differences in the axillary bud growth and fruiting pattern of apple fruiting branches over several years-An approach to regulation of fruit bearing. Scientia Hort. 64:265-281.

Littell, R.C. 1989. Statistical analysis of experiments with repeated measurements. HortScience 24:37-40.

SAS Institute. 1996. SAS/STAT user's guide. SAS Inst., Cary, N.C.

Strydom, D.K. 1991. A proposed high density training system for peaches and nectarines. Annu. Rpt. Michigan State Hort. Soc. 121:12-18. 